\title{
Pendulating endobronchial rhabdomyosarcoma with fatal asphyxia
}

\author{
A ERIKSSON, M THUNELL, G LUNDQVIST
}

From the Institute of Forensic Medicine, University of Umed, and the Department of Lung Medicine, University Hospital of Umed, Umed, Sweden

Among the rare primary pulmonary sarcomas are included the extremely rare rhabdomyosarcomas, of which only 18 non-teratomatous cases have been previously reported, including two cases of tracheal rhabdomyosarcoma. ${ }^{1-5}$

We describe here a case of endobronchial rhabdomyosarcoma where the diagnosis was confirmed by electron microscopy. The patient suffered recurrent asphyxial attacks ending with suffocation because of occlusion of both main bronchi by the highly mobile tumour.

\section{Case report}

A 70-year-old woman was admitted for evaluation of coughing and general deterioration. She had had a cutaneous malignant melanoma between the scapulae removed surgically six years previously and no signs of spread had been found on follow-up. Her past medical history was otherwise unremarkable and she was a non-smoker. Shortly before admission she developed an irritating unproductive cough which became worse when she was recumbent. Chest radiographs showed bronchial occlusion and atelectasis of the right lower lobe.

Repeated cytological analyses of sputa and bronchial lavage specimens showed no malignant cells. At fibreoptic bronchoscopy a tumour was seen to be occluding the right main bronchus, and was falsely interpreted as a metastasis from her previous melanoma.

The patient often sat up in bed as asphyxial attacks were precipitated by certain movements. She deteriorated rapidly and three weeks after admission she died in an attack of acute asphyxia.

At necropsy, an elongated smooth polypoid tumour measuring $4.5 \times 1 \times 1 \mathrm{~cm}$ was found in the right main bronchus. The tumour originated from the distal part of the lower lobe bronchus, attached by a slender elastic stalk. The growth was entirely endobronchial and without extension into the adjacent lung. Because of its elasticity and smooth surface, the tumour could easily be displaced proximally so as to meet the left tracheal wall and occlude the left main bronchus also (fig 1). The bronchi distal to the tumour were filled with mucus and the lung was collapsed. Soft metastatic tissue was found in the adipose tissue in the right axillary region but not elsewhere in the body.

Histologically, the tumour pedicle was found to extend into an intercartilaginous space but not into the adjacent lung tissue. The tumour was partly covered by bronchial epithelium with a high degree of squamous metaplasia.

Address for reprint requests: $\mathrm{Dr} A$ Eriksson, Institute of Forensic Medicine, University of Umeå, Box 6016, S-900 06 Umeå, Sweden.

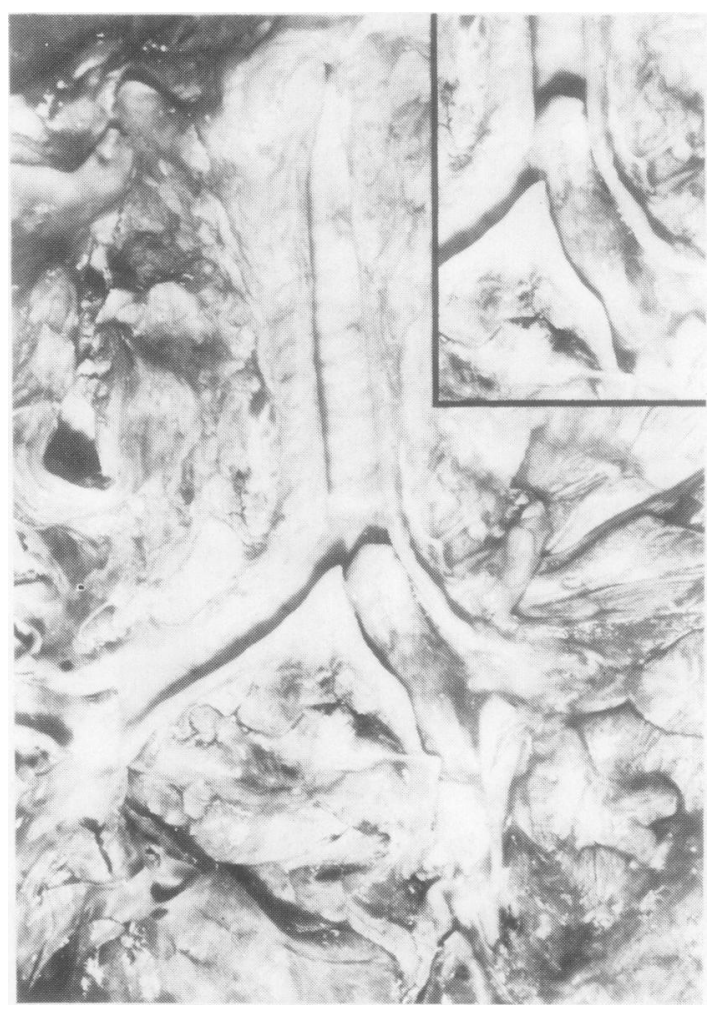

Fig 1 Posterior view of the bronchial tree at necropsy. The sessile polypoid tumour virtually fills the right main bronchus and, because of its elastic pedicle, can easily be dislocated to override the carina (inset).

The growth consisted mainly of fascicles of strap- or spindle-shaped primitive mesenchymal cells (fig $2 a$ ). Some areas had a loose myxoid stroma. The nuclei were sometimes large, pale, and vesicular, sometimes pyknotic. A few atypical mitoses were observed. The cytoplasm was more or less acidophilic, with delicate fibrillations in the cytoplasmic extensions. Occasional cells were larger than this background population, with a deeply acidophilic cytoplasm and somewhat larger nuclei, typical of rhabdomyoblasts.

Cross-striation was suspected in only very few cells. Therefore parts of the paraffin-embedded tissue were dewaxed and processed for electron microscopy. In spite of 


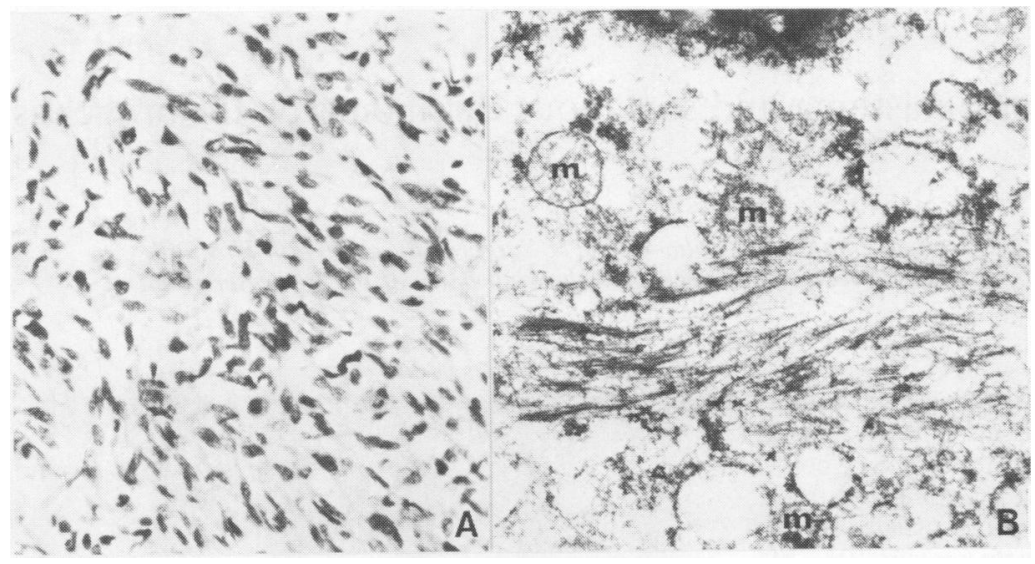

Fig 2 (a) Appearance of embryonal rhabdomyosarcoma with interwoven fascicles of spindle-shaped tumour cells with moderate polymorphism and heterochromatic nuclei. Acidophilic cytoplasm is often seen streaming from one end. Occasional giant rhabdomyoblasts and several pyknotic nuclei are also seen. Van Gieson stain-magnification $\times 170$. (b) Electron micrograph of an autolytic tumour cell. In spite of autolysis, poorly arranged myofilaments with focal densities are seen. Nucleus (upper edge), mitochondria $(m)-$ magnification $\times$ 15000.

poor preservation of ultrastructure, several cells with primitive myofibrillar material were evident (fig 2b), confirming the diagnosis of rhabdomyosarcoma.

\section{Discussion}

This case represents a case of embryonal rhabdomyosarcoma of the bronchus in an elderly individual. There can be little doubt that the tumour arose primarily in the bronchus, and the macroscopic and light microscopic appearance of the tumour are sufficiently typical to make the diagnosis certain..$^{367}$ Cells containing cross-striations were few, but are recognised in only about $50 \%$ of cases of embryonal rhabdomyosarcoma and are not required for the diagnosis. ${ }^{6}$ The electron microscopic picture of primitive myofibrils confirmed the diagnosis conclusively, ${ }^{7}$ and illustrates the value of electron microscopic analysis of poorly differentiated sarcomas.

The origin of the striated muscle fibres has been much debated and two main hypotheses have been presented. Some have suggested that they emerge from undifferentiated mesenchymal cells which have retained their ability to develop into rhabdomyocytes. Others believe that they develop from displaced muscle tissue and thus represent teratomas. ${ }^{3}$ It may be that the rhabdomyosarcomas arising in pre-existing malformations represent tumours originating from rhabdomyomatous tissue displaced during fetal development. However, in the present and similar cases of elderly persons with short histories of bronchial obstruction, and without malformations or teratomas, it seems more reasonable that the tumours originated from aberrantly differentiated mesenchymal tissue.

The present tumour was purely endobronchial. Purely endotracheal rhabdomyosarcomas have also been described. ${ }^{25}$ Such polypoid tumours in the airways may not be diagnosed by the cytological examination of sputum, since the exfoliated cells are derived from the covering epithelial layer. Three other cases ${ }^{3}$ have exhibited both a major diffuse and a minor endobronchial part, while the tumours described by other authors have been purely pulmonary. The mode of growth may depend on whether they are growing from a free surface or not.
The symptoms described in the present case do not seem to have been recorded previously for pulmonary rhabdomyosarcoma. Several mesenchymal tumours of the respiratory tract, however, also may form pendulating polyps. The obstructive symptoms produced by such polypoid tumours are mainly restricted to stasis, atelectasis, and subsequent infection. Exceptionally, acute symptoms occur-for example, wheezy dyspnoea and stridor, especially in cases of tracheal tumours. Lethal asphyxia, however, seems to be rare. Our review of the literature has revealed only three cases of suffocation from polypoid tumours, all situated in the upper airways. These include one carcinosarcoma, ${ }^{8}$ one undifferentiated carcinoma, ${ }^{9}$ and one lipoma. ${ }^{10}$

\section{References}

' Fabretto DA, Paganelli M, Caiafa L. Il rabdomiosarcoma primitivo del polmone. Rassegna della letteratura e rapporto di un caso. Chir Ital 1965;17:430-54.

${ }^{2}$ Ho K-L, Rassekh ZS. Rhabdomyosarcoma of the trachea: first reported case. Hum Pathol 1980;11:572-4.

${ }^{3}$ Lee SH, Rengachary SS, Paramesh J. Primary pulmonary rhabdomyosarcoma: a case report and review of the literature. Hum Pathol 1981;12:92-6.

${ }^{4}$ Mehrotra ML, Gupta IM, Chopra G, Srivastava TP. A pleomorphic-cell sarcoma of lung with ball metastases in the heart. Ind J Chest Dis 1973;15:240-5.

${ }^{5}$ Zakrzewski A, Szlęzak L, Skowroński S, Skowrońska I, Przybora L. Mięsak prązkowanokomórkowy tchawicy. Otolaryngol Pol 1971;25:79-82.

${ }^{\circ} \mathrm{Fu}$ Y-S, Perzin KH. Nonepithelial tumors of the nasal cavity, paranasal sinuses, and nasophanynx. A clinicopathologic study (V). Skeletal muscle tumors (rhabdomyoma and rhabdomyosarcoma). Cancer 1976;37:364-76.

${ }^{7}$ Sulser H. Das Rhabdomyosarkom. Alters- und Geschlechtsverteilung, Lokalisation, patologische Anatomie und Prognose. Virchows Arch, A Path Anat Histol 1978;379:35-71.

${ }^{8}$ Drury RAB, Stirland RM. Carcino-sarcomatous tumours of the respiratory tract. J Path Bact 1959;77:543-54.

${ }^{9}$ Brunn H, Goldman A. Differentiation of benign from malignant polypoid bronchial tumors. Surg Gyn Obstet 1940;71:703-22.

${ }^{10}$ Penfold JB. Lipoma of the hypopharynx. Br Med J 1952;1:1286. 